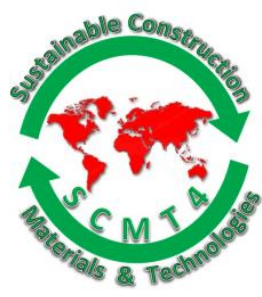

SCMT4

Las Vegas, USA, August 7-11, 2016

\title{
External CFRP Reinforcement Impact on RC Wall Behavior, Subjected to Quasi-Static Cyclic Load Test
}

\author{
Samiullah QAZI ${ }^{1}$, Laurent MICHEL ${ }^{2 a}$ and Emmanuel FERRIER ${ }^{2 b}$ \\ ${ }^{I}$ CIVIL Engineering, COMSATS Institute of Information Technology, PAKISTAN, \\ Email: <engrsami@gmail.com>. \\ ${ }^{2}$ Génie CIVIL, Université Lyon 1, France, \\ ${ }^{2 a}$ Email: <laurent.michel@univ-lyon1.fr>; ${ }^{2 b}$ Email: <emmanuel.ferrier@univ-lyon1.fr>.
}

\begin{abstract}
This study addresses the applicability of CFRP partial strengthening technique on the short RC walls, weak in shear, to attain reasonable strength and drift without deterioration in the wall dissipation capacity under seismic loading. Three RC walls were tested: one control wall and two walls strengthened with CFRP, using two different bonding configuration. The $\mathrm{RC}$ walls represents at 1:3 scale the lower part of a shear wall of an existing building typically five to eight stories designed prior seismic loading consideration i.e., in 1960 in Europe (Switzerland and France). The walls were tested when subjected to a constant axial load along with displacement controlled cyclic lateral loading applied at the head beam level. The strengthened walls showed satisfactory performance with improved shear strength and drift compared to control wall. The test result analysis discussion includes stiffness, ultimate load capacity, deformability, and energy dissipation.
\end{abstract}

\section{INTRODUCTION}

In 60's, the reinforced concrete (RC) walls were basically designed as bracing system to withstand vertical and wind load as in Switzerland [Greifenhagen and Lestuzzi 2005] and Hong Kong [Su and Wong 2007]. However, in recent years, they are considered as an integral part of building structures. Postearthquake surveys have highlighted their significance in confining the earthquake induced damage [Sezen et al. 2003; Fintel 2012]. It constitute the seismic force resisting system [Park and Paulay 1975; Thomas Paulay 1975; Mau and Thomas 1986]. Though reinforced concrete walls are used in building to dissipate seismic induced energy they too are vulnerable to seismic damage. The main causes of damage are: occurrence of unpredictable high seismic activity, improper designing and construction flaws [Inoue et al. 1997, Oh YH. et al. 2002, Brun M. et al. 2004]. The aforementioned circumstances necessitates the seismic strengthening of existing weak RC walls to meet the modern seismic design code requirements. Therefore, there is a need to improve RC shear wall strength and deformability while not deteriorating the wall energy dissipation capacity.

The anticipated failure mode of an existing walls determines the appropriate strengthening technique. RC wall load response behaviour depends to a great extent on its height to length ratio. The RC Wall which 
has $\mathrm{H} / \mathrm{L}$ ratio lesser than 2 is considered as short and the wall that has $\mathrm{H} / \mathrm{L}$ ratio greater than 2 is considered as slender/long wall [Brun M. et al. 2003]). Short wall endure high shear stress as compared to slender wall. The failure modes of short wall are sliding apart of wall from it supporting foundation, diagonal shear cracks development with in wall and concrete crushing at wall toe [Lefas et al. 1990, Paulay T. et al. 1982, Brun M. et al. 2003, Greifenhagen and Lestuzzi 2005].

To strengthen RC structural elements numerous strengthening techniques have been developed and implemented in recent years. These are: steel-plate bonding, pre-stressing, reinforced concrete jacketing and fibre-reinforced polymer (FRP) reinforcement. Among these techniques, the FRP strengthening technique is the most popular because of its light weight, easy implementation and high resistance to corrosion. Most of the research has been carried out in improving the performance of columns and beams with use of CFRP. However, little research has been carried out on investigating the influence of CFRP reinforcement on the performance of shear wall with insufficient lap splices, poor confinement, and weakly reinforced. Researchers [Paterson and Mitchell 2003; Khalil and Ghobarah 2005; Layssi et al. 2012] investigated the effect of CFRP wrapping technique in the seismic retrofit of existing weak shear walls. However, the CFRP wrapping technique is not suitable, in general, for shear walls. Because mostly the shear walls are connected to columns or are constructed in the form of $U$ or $L$ shapes due to which the wall edges are not accessible to wrap CFRP around them.

Some strengthening techniques are applied on concrete wall with RC frame. However research work on strengthening RC wall and testing it as a sole structural element is rather limited. In this research work the $\mathrm{RC}$ wall are tested as cantilever specimen to observe the full Impact of CFRP in improving its performance. Also the CFRP sheets/strips are bonded to the wall faces, while keeping some patches of concrete surface open. This arrangement is made as the CFRP material due to its characteristic stiff behavior reduce to the wall dissipation capacity when the CFRP is applied on the entire wall surface. The $\mathrm{RC}$ wall dissipate induced energy due to internal rebar yielding and friction in between cracked surfaces. The bonding technique was implemented on the wall two faces without using any additional arrangement at the wall ends. However to limit CFRP intermediate crack debonding, CFRP mesh anchors are installed on the wall foundation joint and wall panel surface.

This study investigates the influence of external CFRP reinforcement on load response behavior of short RC. In total three RC walls, designed under-reinforced to fail in shear, were fabricated. Two out of these three specimens were afterward strengthened with CFRP. Test results discussion includes failure modes, hysteresis curve, stiffness, dissipated energy and damage factor.

\section{TEST SETUP AND SPECIMENS}

The object of this research work was to assess the complete performance of the strengthened wall up to failure. Therefore, instead of testing a multi-storey RC wall or RC wall panel within RC frame, only one panel of the RC wall was tested. Three wall specimens were constructed and tested: one control wall specimen and two CFRP strengthened wall specimens using two different retrofit schemes. The concrete compressive strength was $40.6 \pm 0.4 \mathrm{MPa}$, used for specimen construction. The internal steel rebar average yield strength, ultimate strength, and modulus of elasticity were evaluated to be equivalent to 500 $\mathrm{MPa}, 570 \mathrm{MPa}$, and $200 \mathrm{GPa}$, respectively. The CFRP fabric used had a tensile strength of $825 \mathrm{MPa}$, tensile modulus equivalent to $70.5 \mathrm{MPa}$ and an ultimate strain of $0.85 \%$. The epoxy resin used had a tensile strength, modulus, ultimate strain and glass transition temperature of $55 \mathrm{MPa}, 3200 \mathrm{MPa}, 2.3 \%$ and $56^{\circ} \mathrm{C}$, respectively.

To simulate seismic loading the test specimens were subjected to displacement control lateral cyclic loading under a constant axial load, with the walls acting as cantilevers (Figure 1). The axial load ratio (ratio of the applied axial load to the axial load capacity) at the concrete section has a significant influence 
on the shear wall's performance, deformability and failure modes [Lefas et al. 1990; Oh et al. 2002; Su and Wong 2007; Lestuzzi and Bachmann 2007]. In this case a constant axial compression load of $110 \mathrm{kN}$ was sustained at head beam. To simulate seismic actions specimens were subjected to reverse static cyclic load test. According to recommendation of ACI [ACI T1.101, 2001], specimens were subjected to three full cycles at each level. Due to variation made in external CFRP reinforcement configurations of all specimens, the lateral displacement load levels were based on drift instead of ductility for ease in performance comparison. Since deformation based methods promise more realistic results than the force based methods, the former should be applied on existing buildings too [Priestley 1997]. The applied lateral displacement load levels were maintained at drift levels of $0.1 \%, 0.2 \% \ldots 0.8 \%, 1 \% \ldots 1.8 \%$. with a speed of $10,20 \ldots 80,100,120.180 \mathrm{~mm} / \mathrm{min}$, respectively.

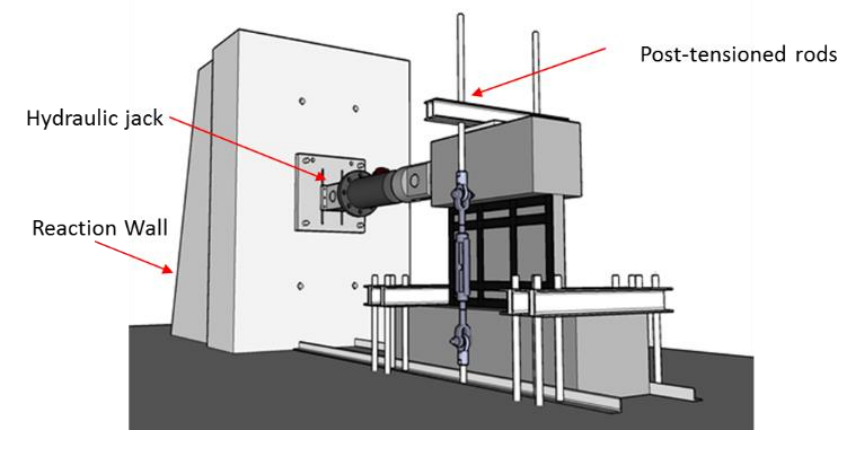

Figure 1. Test setup

Control Specimen S3. The RC wall panel geometry represents the lower part of an existing building shear wall, constructed in 60's, in Switzerland at a 1:3 scale [Greifenhagen 2005 \& S. Qazi et al. 2015]. The slenderness ratio (h/l) of the wall panel is equal to $0.678<2$, with a height and length of $610 \mathrm{~mm}$ and 900mm, respectively. According to Eurocode [EN 1998-1], Ref. 5.4.7.2.1 the minimum reinforcement ratio is $0.4 \%$. However in this research work the specimens were fabricated under-reinforced. The vertical and horizontal reinforcement ratio with in wall panel was kept equal to $0.3 \%$ and $0.2 \%$ respectively and a clear cover equivalent to $2 \mathrm{~cm}$ was kept. Prior wall fabrication, the premature shear failure in wall panel was confirmed through analysis done according to ACI Code 318-08. To depict the infield condition, the test specimen head and foundation blocks were fabricated first. These were then cured for 28 days and later on aligned on floor with wall panel mold to fabricate it. The wall panels were then cured for 28 days, prior subjecting to load test.

Retrofitted specimens SR4 \& SR6. The choice of a reinforcement pattern is always difficult due to some antagonistic parameters (e.g., maximum load and energy dissipation). The adopted external CFRP reinforcement pattern was based on the crack pattern observed in the RC wall load test. Two pattern were used in first case (SR4) the CFRP strips were bonded parallel to wall steel reinforcement while in second (SR6) the CFRP strips were bonded in direction orthogonal to diagonal cracks to bridge the cracks more efficiently (Figure 2). The composite reinforcement was made from carbon fabric bands that were $50 \mathrm{~mm}$ wide and $0.48 \mathrm{~mm}$ thick. The Young's modulus is $105 \mathrm{GPa}$, and the ultimate strength is $1400 \mathrm{MPa}$. The concrete surfaces were mechanically sanded to achieve a good quality bond between the concrete and the CFRP.

The two faces of the wall were made smooth by sandblasting before strengthen them with CFRP. The CFPR strengthening configuration applied in shown in figure. To limit CFRP strip debonding in vicinity of wall foundation joint and efficient transfer of load from CFRP to foundation block, all the vertical bands were connected to the lower foundation through anchor strand composites. This extra reinforcement confirmed better use of the mechanical properties of carbon bands. The employed mesh anchor had an 
overall length of $40 \mathrm{~cm}$ and consisted of 26 fiber tows. Each anchor was embedded in drilled hole made in foundation block up to a length of $150 \mathrm{~mm}$ (5.90 in.) and its remaining length was splayed over the vertically bonded FRP strips. This was then over-bonded by a CFRP strip splayed in direction perpendicular to wall vertical axis. In specimen SR6, to limit CFRP strips debonding with in wall panel, mesh anchors were placed in holes, which were drilled within the wall panel at CFRP strips intersection point.

CFRP Anchors. They are made up of CFRP fiber tow, by winding it around two nails, fixed apart a distance equal to four times the required anchor length $(40 \mathrm{~mm})$. The tensile strength of a mesh anchor of 26 fiber tows was equivalent to $22 \mathrm{kN}$. The mesh anchors utilized here has proved its significance in limiting the intermediate crack debonding at L shape joint [Qazi et al. 2013]. The mesh anchor installed at wall foundation joint had cross sectional area equivalent to $80 \mathrm{~mm}^{2}$. They are made up of CFRP fiber tow that contained $12 \mathrm{k}$ filaments, by winding it around two nails, fixed apart a distance equal to two times the required anchor length $(80 \mathrm{~cm})$. The tensile strength of a mesh anchor of 26 fiber tows was equivalent to $22 \mathrm{kN}$.

\section{RESULTS AND DISCUSSIONS}

Failure modes. Figure 3 shows a picture of the failed specimen S3. At test end a flat crack developed along the construction joint, which covered the entire wall length. This was accompanied with concrete crushing and lap splice rebar buckling at wall toe, at both ends.

Figure 4 show photos of failed specimen SLR4. In this case diagonal cracks developed at wall free end. Initially a crack developed in the wall, at one fourth of its height, at induced displacement of $6.48 \mathrm{~mm}$ and load of $170.5 \mathrm{kN}$. Another crack developed diagonally at the wall mid height at induced displacement of $8.1 \mathrm{~mm}$ and load of $150 \mathrm{kN}$. Both cracks spread towards the wall foundation joint and were not superficial as they developed at both wall faces including wall end. The cracks formed at wall free end because the test was initiated with pushing therefore at each load level the wall free end first experienced compression and then tension. This initial compression initiated CFRP debonding and buckling at free end as it cannot withstand compression load. This in turn resulted in tensile cracks initiation at the wall free end during pulling as the RC section could not sustained higher tensile stresses. The CFRP debonding is shown in second photo (Figure 4). The test was stopped at displacement load level of $9.72 \mathrm{~mm}$ due to formation of flat crack at the wall foundation joint and reduction in sustained load up to $30 \%$. The flat crack at wall foundation joint originated at wall free end and surpassed at half length of the wall. At the final stage of test, toe crushing and rebar yield at the wall free end was observed.
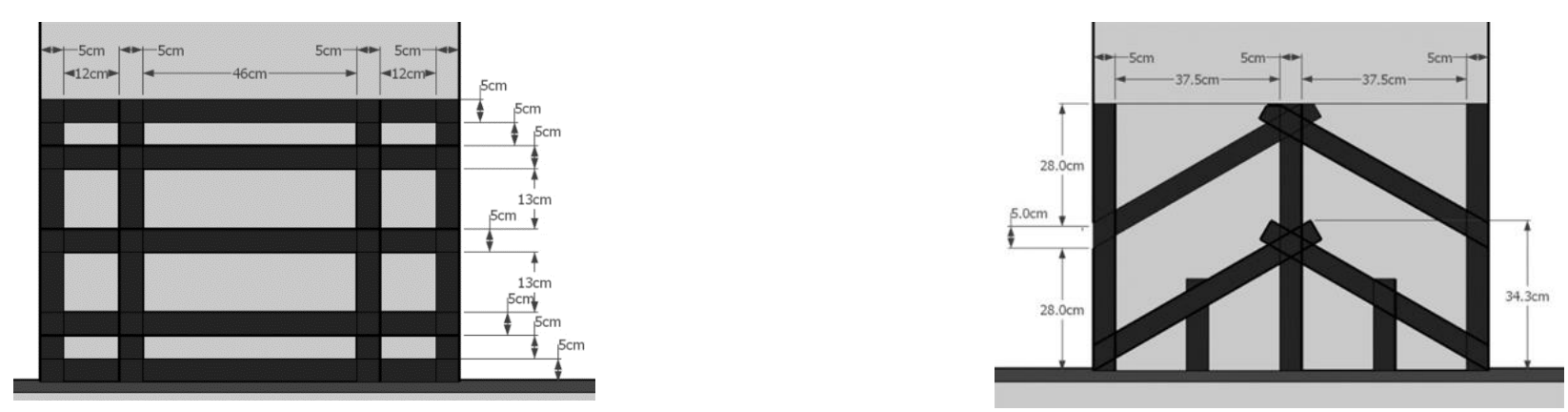

Figure 2. CFRP reinforcement schematic detail (Wall SR4 and SR6) 


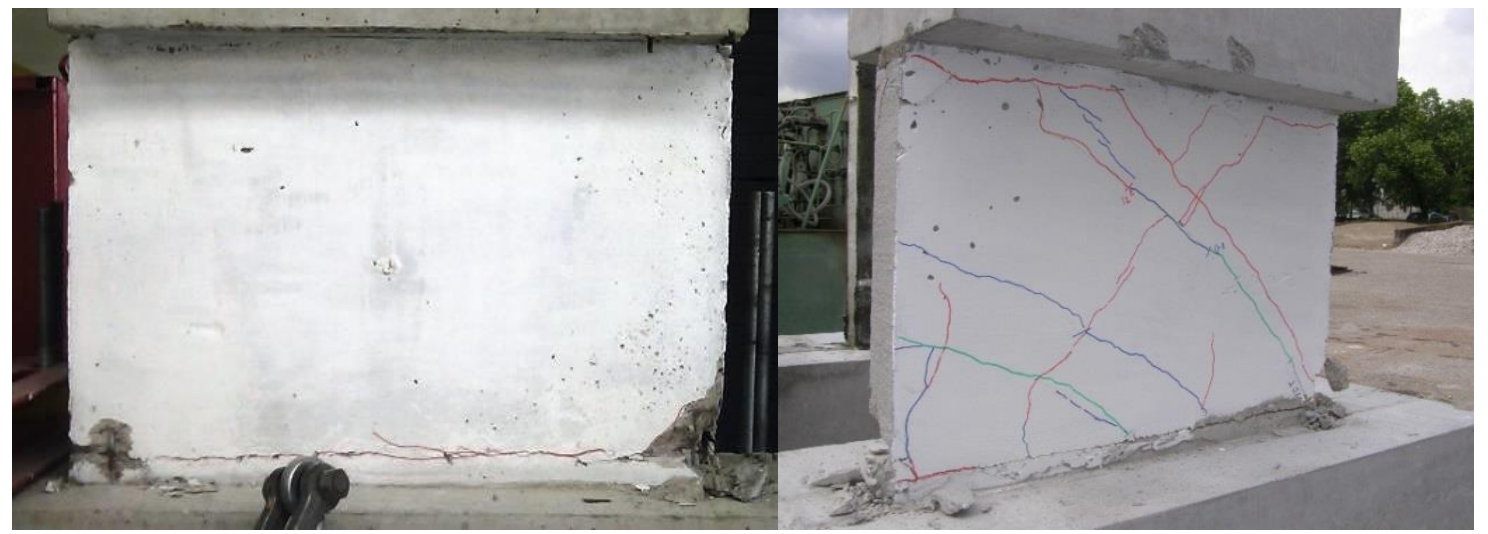

Figure 3. Specimen S3 Failure pattern
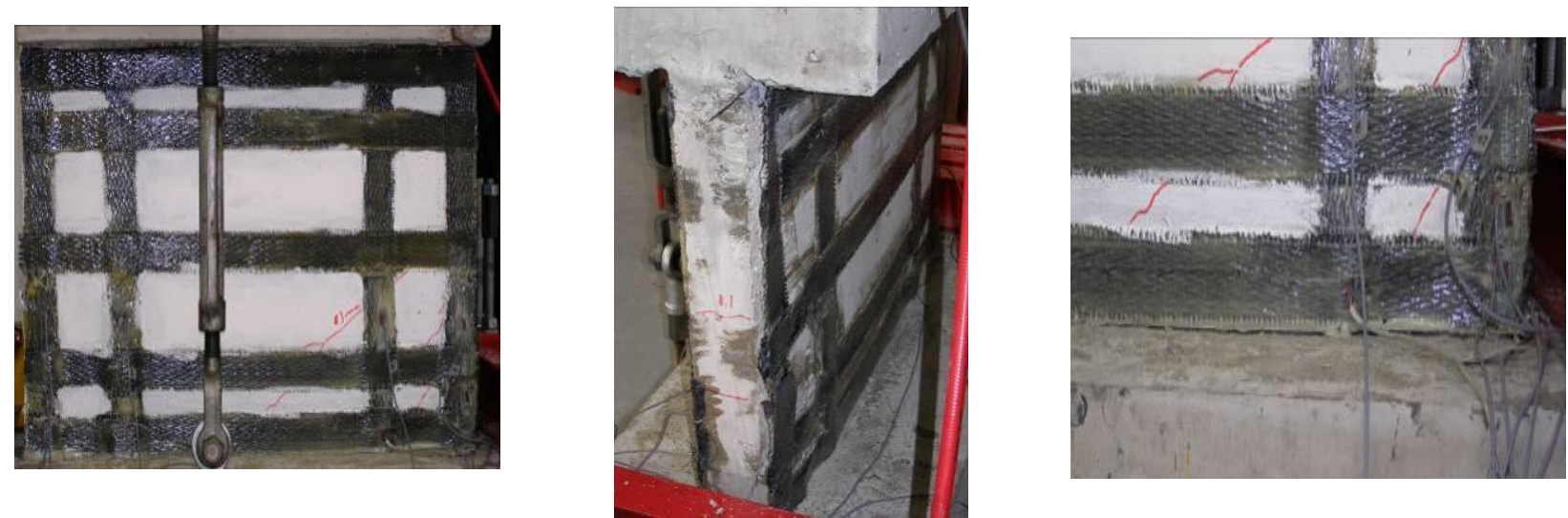

\section{Figure 4. Specimen SR4 Failure pattern}

Though specimen SR6 showed an overall improvement in ductility and strength as compared to SR5, yet the wall panel crack pattern was almost identical in the two. Figure 5 depicts specimen SR6 failure pattern. At induced load level of $8.1 \mathrm{~mm}$ two diagonal cracks, one at each end appeared at the wall panel lower half. These cracks propagated across the diagonally bonded CFRP strip and touched the wall bottom in vicinity of its mid-length. However the diagonally bonded strips reduced the crack widening to a certain extent. Afterwards a number of diagonal cracks developed within wall panel lower half middle portion accompanied with another diagonal crack along wall free end upper diagonal while touching the CFRP strip bonded in the same direction. At test end, debonding was observed in the CFRP strips located within the wall lower half. It included debonding of strips along the wall diagonals and the interior vertical strips. On the other hand in wall upper half portion, the vertically bonded strip located at wall mid-length, ruptured beneath the intersection point of diagonally bonded CFRP. In this case the CFRP debonding was not severe as in case of SR5 due to the improvement made in the transverse mesh anchors introduced at CFRP strip intersection points.

Hysteresis Curve. The hysteresis curves (Figure 6) depict the variation in the cyclic load response behavior of all the specimens (S3, SR4 \& SR6). The observed max load sustained by S3, SR4 and SR6 is $138.69,170.53$ and $169.44 \mathrm{kN}$ respectively. The hysteresis curves indicate an increase in the initial stiffness in specimens SR4 and SR6 as compared to S3. The relatively higher initial stiffness of SR6 in comparison to SR4 is owed to the additional transverse mesh anchor arrangement made within the wall panel. The pinching of hysteresis curve of specimen 
SR4 and SR6 as compare to S3 at identical load level, after the crack initiation, point out that the additional CFRP external reinforcement depreciate the dissipation capacity of the RC wall. The comparative analysis of SR4 and SR6 indicates a relatively smooth decline in the sustained load of SR6 after exceeding their ultimate capacity. This difference in behaviors is owed to transverse mesh anchor which retained the CFRP intact with concrete surface and thus avoided abrupt failure on a large scale.
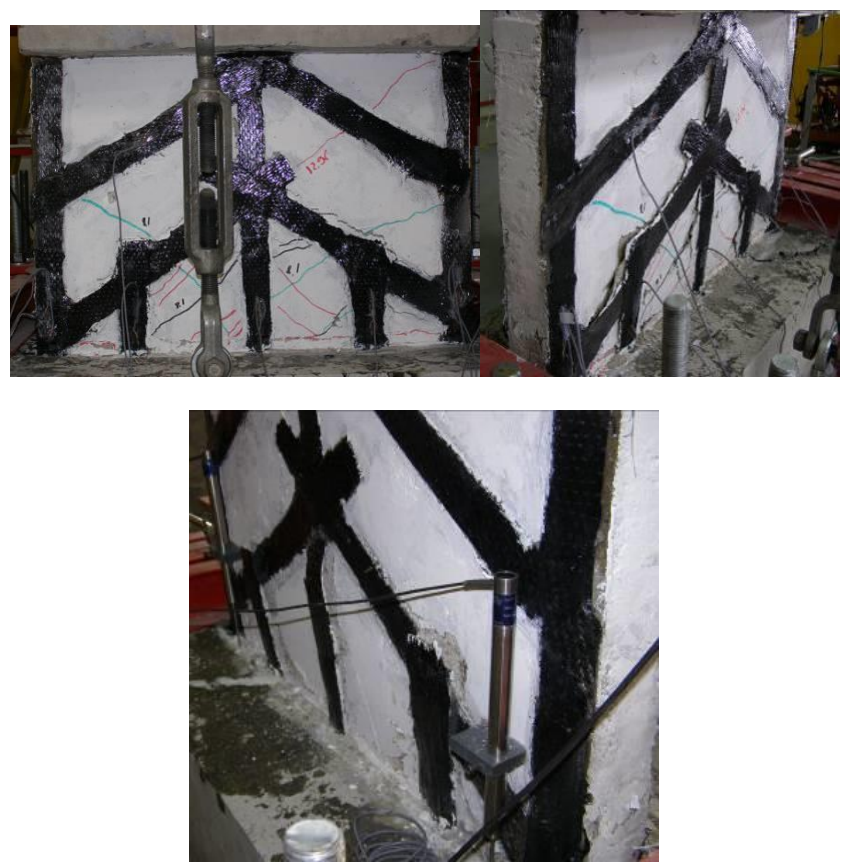

Figure 5. Specimen SR6 Failure pattern

Elastic and dissipated energy. For test specimens S3, SR4 and SR6 the total, elastic and dissipated energy values are given in Figure 7 in the form of bar charts. The energy values correspond to half load cycles and were evaluated by use of trapezoidal rule. The total, elastic and dissipated energy were evaluated by computing the area under the loading curve, under the un-loading curve and in between the loading and unloading curves, respectively. In all the three specimens the dissipated energy at each load level decreased with relative increase in cycle number, due to smoothening of the cracked surfaces. Specimens S3 and SR6 at their ultimate drift level (0.8 and 1.2\%, respectively) exhibited higher amount of energy dissipation in comparison to their elastic energy (E.E).

\section{CONCLUSION}

The CFRP reinforcement pattern adopted in this research work proved successful in limiting crack propagation to some extent and improved the performance of the RC wall that was weakly reinforced. This research work highlights the positive influence of external CFRP reinforcement on RC short wall. The CFRP strips bonded to RC wall panel did improve their ultimate load capacity, ductility, and limited the crack propagation to a certain extent. The mesh anchor placement at wall foundation joint remedied the joint failure due to improper reinforcement arrangement in this region. They also limited CFRP strips debonding problem, a major concern in case of utilization of external FRP reinforcement technique, by 
transferring load effects from the bonded strips to lower foundation block. The partial FRP strengthening adopted here proved to be successful as it did not deteriorated the RC wall energy dissipation capacity. $\mathrm{RC}$ structural elements dissipate induced energy as a result of friction in between concrete cracks and rebar yielding. This arrangement ensured concrete cracking within wall panel to some extent which in turn resulted in energy dissipation.

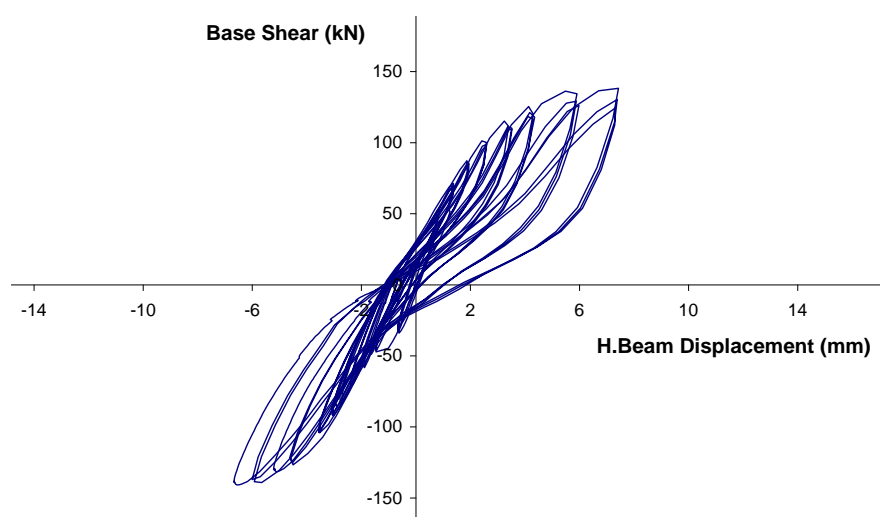

(a) S3

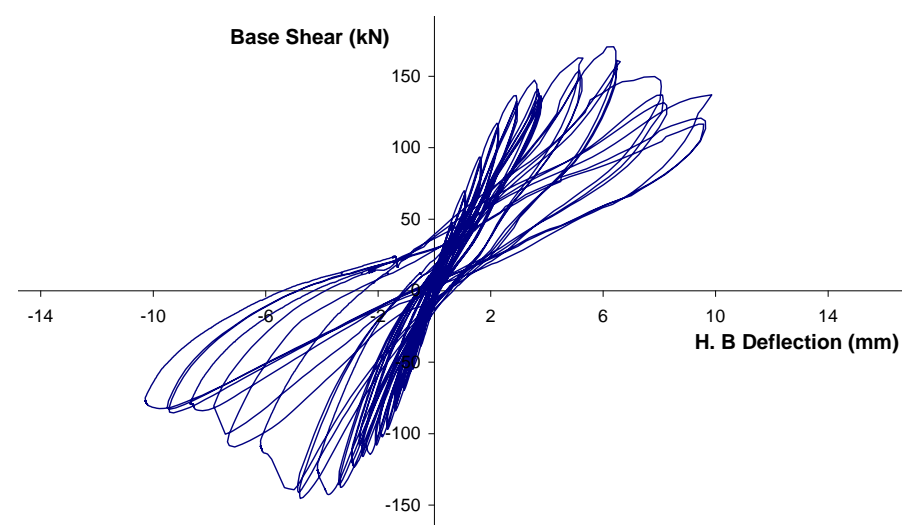

b) SR4

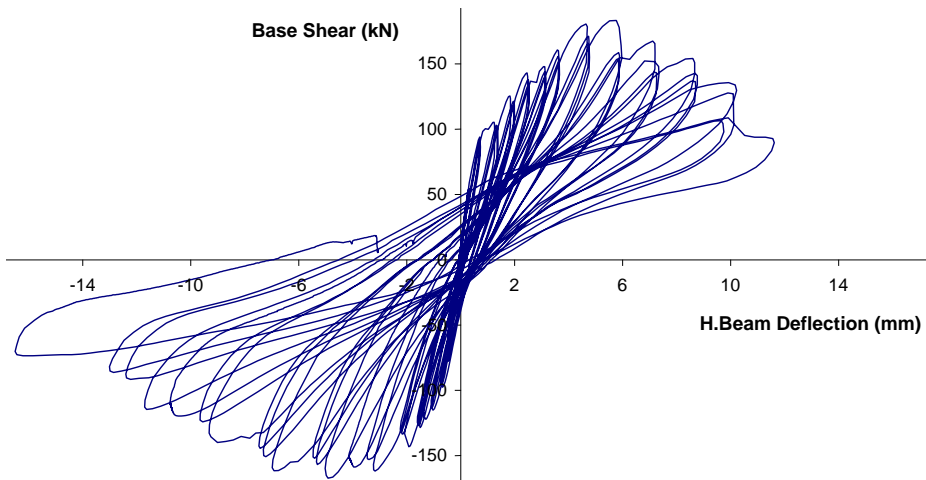

(c) SR6

Figure 6. Hysteresis curve 
S3-Push Pull Half Cycle

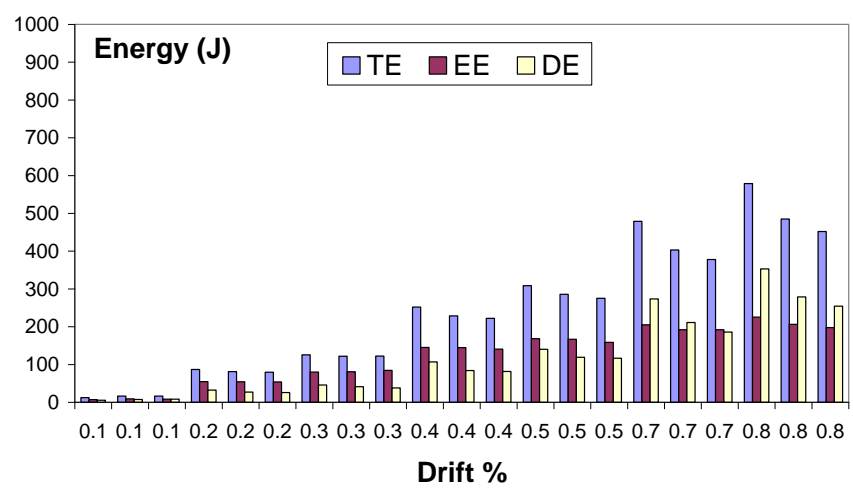

SR4-Push Pull Half Cycle

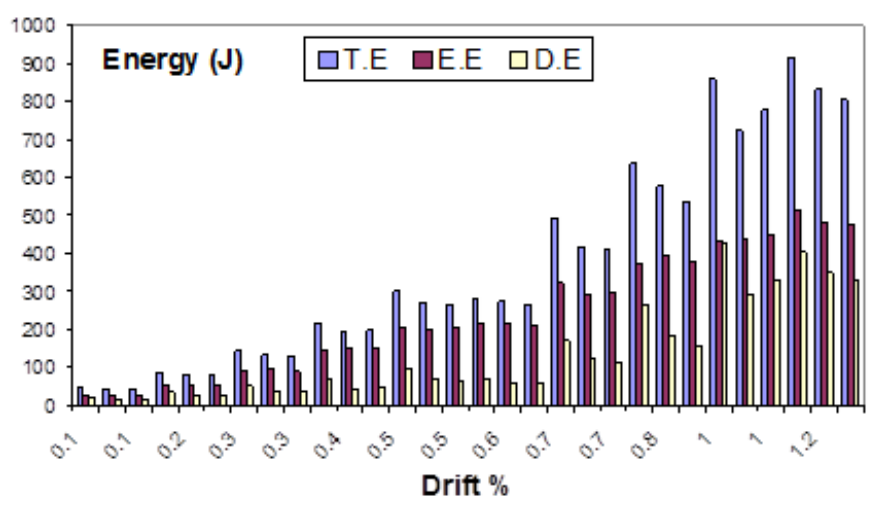

SR6-Push Pull Half Cycle

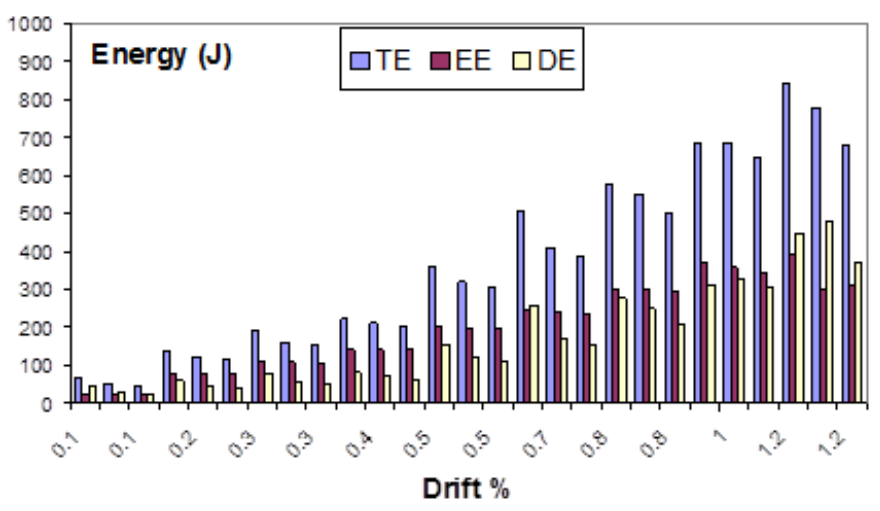

Figure 7. S3, SR4 and SR5 T.E, E.E and D.E bar charts

\section{REFERENCES}

ACI Innovation Task Group 1 and Collaborators, "Acceptance Criteria for Moment Frames Based on Structural Testing (ACI T1.1-01) and Commentary (ACI T1.1R-01)," American Concrete Institute, Farmington Hills, MI, 2001. 
Brun M, Reynouard JM, Jezequel L. A simple shear wall model taking into account stiffness degradation. J Eng Struct 2003; 25(1):1-9.

Brun M, Reynouard JM, Jezequel L, Ile N. Damaging potential of low-magnitude near-field earthquakes on low-rise shear walls. J Soil Dyn Earthquake Eng 2004;24(8):587-603.

EN 1998-1: Eurocode 8- Design of structures for earthquake resistance - Part 1: General rules, seismic actions and rules for buildings, 2004.

FINTEL, M., 2002. Performance of buildings with shear walls in earthquakes of the last thirty years. PCI journal, 40 (3), 62-80.

Greifenhagen, C. and Lestuzzi, P., 2005. Static cyclic tests on lightly reinforced concrete shear walls. Engineering Structures, 27 (11), 1703-1712.

Inoue N, Yang K, Shibata A. Dynamic nonlinear analysis of reinforced concrete shear wall by finite element method with explicit analytical procedure. J Earthquake Eng Struct D 1997;26(9):967-86.

Khalil A, Ghobarah A. Behaviour of rehabilitated structural walls. J Earthquake Eng 2005;9(3):371-91.

Layssi H, Cook WD, Mitchell D. Seismic response and CFRP retrofit of poorly detailed shear walls. J Compos Constr - ASCE 2012;16(3):332-9.

Lefas, I.D., Kotsovos, M.D., and Ambraseys, N.N., 1990. Behavior of reinforced concrete structural walls: strength, deformation characteristics, and failure mechanisms, 87 (1), 23-31.

Lestuzzi, P. and Bachmann, H., 2007. Displacement ductility and energy assessment from shaking table tests on RC structural walls. Engineering Structures, 29 (8), 1708-1721.

Mau, S.T. and Thomas, T.C.H., 1986. Shear Design and Analysis of Low-Rise Structural Walls. ACI Journal Proceedings, 83 (2), 306-315.

Oh, Y., Han, S.W., and Lee, L., 2002. Effect of boundary element details on the seismic deformation capacity of structural walls. Earthquake Engineering \& Structural Dynamics, 31 (8), 1583-1602.

Paterson J, Mitchell D. Seismic retrofit of shear walls with headed bars and carbon fiber wrap. J Struct Eng - ASCE 2003;129(5):606-14.

Park, R. and Paulay, T., 1975. Reinforced Concrete Structures. Wiley. Newyork: John Wiley \& Sons.

Paulay, T. and Priestley, M.J.N., 1982. Ductility in earthquake resisting squat shear wall.pdf. ACI Journal, 79 (4), 257-69.

Priestley MJN. Displacement-based seismic assessment of reinforced concrete buildings. Journal of Earthquake Engineering 1997;1(1): 157-92.

Qazi S, Michel L, Ferrier E. Experimental investigation of CFRP anchorage systems used for strengthening RC joints. J Compos Struct 2013;99:453-61.

Sezen, H., Whittaker, A.S., Elwood, K.J., and Mosalam, K.M., 2003. Performance of reinforced concrete buildings during the August 17, 1999 Kocaeli, Turkey earthquake, and seismic design and construction practise in Turkey. Engineering Structures, 25 (1), 103-114.

Su, R.K.L. and Wong, S.M., 2007. Seismic behaviour of slender reinforced concrete shear walls under high axial load ratio. Engineering Structures, 29 (8), 1957-1965.

Thomas Paulay, 1975. Design Aspects of Shear Walls for Seismic Areas. Canadian Journal of Civil Engineering, 2 (3), 321-344. 